\title{
Rational design of sustainable polyurethanes from castor oil: towards simultaneous reinforcement and toughening
}

\author{
Xu-Pei An ${ }^{1}$, Jia-Hui Chen ${ }^{1}$, Yi-Dong Li $^{1^{*}}$, Jiang $\mathrm{Zhu}^{2}$ and Jian-Bing Zeng ${ }^{1,2^{*}}$
}

\begin{abstract}
Sustainable polyurethanes prepared from castor oil and diisocyanates show very low strength and toughness, due to the highly cross-linked and flexible structure. Herein, we report a new strategy to simultaneously reinforce and toughen castor oil-based polyurethane via incorporating a stiff component (isosorbide, IS) to enhance network stiffness and reduce crosslink density. The crosslinking degree decreases while the strength, moduli, ductility and heat resistance significantly increase accordingly with increasing IS content. The tensile behaviors are tunable over a broad range (either as elastomers or as plastics) depending on the compositions. The polyurethanes show excellent thermal stability with onset decomposition temperature higher than $280^{\circ} \mathrm{C}$. The investigation provides a new hint for future design and fabrication of high performance sustainable polymers from other vegetable oils.
\end{abstract}

Keywords: sustainable polyurethane, castor oil, isosorbide, crosslink density, mechanical property

\section{INTRODUCTION}

Exploitation of sustainable polymers from renewable feedstocks has attracted increasing attention, due to the continuously increased environmental concerns and resource crisis related to traditional fossil-based polymers [1-6]. Inexpensive vegetable oils, with various functional groups such as $\mathrm{C}=\mathrm{C}$ double bond, ester, hydroxyl and epoxy groups depending on the origins, are thought as the ideal alternatives to fossil resources in production of novel sustainable polymers [7-9]. It is noted that the sustainable polymers synthesized directly from vegetable oils usually show poor mechanical performance leading to limited application [10-12]. Although high performance polymers such as polyamides, polyesters and epoxy thermosets can be prepared from monomers derived from vegetable oils through well-designed chemistry techniques, the conversion of vegetable oils to monomers increases the cost of the resultant materials inevitably $[3,7,13]$. If high performance sustainable polymers can be prepared from vegetable oils directly without undergoing monomer conversion step, they would be much more commercially competitive due to the increased cost-efficiency. However, it remains a challenge to convert vegetable oils to high performance polymers directly.

Castor oil (CO) with naturally occurring hydroxyl groups is a good choice for polyurethane production [1416]. In fact, it had played an important role in the early stage of polyurethane industry before the commercial availability of synthetic polyols [15]. CO-based polyurethanes exhibit some appealing properties such as water resistance and flexibility [15]. However, they were usually used in non-structural applications such as coatings and adhesives [17-19]. The poor mechanical properties hindered their use in structural applications, which is probably responsible for abandonment of castor oil in the modern polyurethane industry. The requirement for sustainable development has triggered renewed interest in fabrication of polyurethanes from castor oil in recent years [20-25].

The chemical structures of vegetable oils derived polymer networks such as castor oil-based polyurethane and dicarboxylic acid cured epoxidized soybean oil are characterized by the high crosslink density and the high flexible backbones, which endow the polymer networks with poor mechanical properties [11,26-28]. Although crosslinking would enhance mechanical strength [29], it would meanwhile reduce the ductility of polymer networks if the degree of crosslinking were excessively high.

${ }^{1}$ School of Chemistry and Chemical Engineering, Southwest University, Chongqing 400715, China

${ }^{2}$ College of Materials and Chemical Engineering, Chongqing University of Arts and Sciences, Chongqing 402160, China

* Corresponding authors (emails: liyidong@swu.edu.cn (Li YD); jbzeng@swu.edu.cn (Zeng JB)) 
Table 1 Feeding contents and the contents of soft segment (SS) and hard segment (HS) of the samples

\begin{tabular}{|c|c|c|c|c|c|}
\hline Sample & $\mathrm{CO}(\mathrm{wt} \%)$ & IS (wt\%) & HDI (wt\%) & SS (wt\%) & HS (wt\%) \\
\hline COPU & 80.50 & 0 & 19.50 & - & - \\
\hline C9I1PU & 67.52 & 7.50 & 24.98 & 83.95 & 16.05 \\
\hline C8I2PU & 56.14 & 14.03 & 29.82 & 69.82 & 30.18 \\
\hline C7I3PU & 46.20 & 19.80 & 34.00 & 57.43 & 42.57 \\
\hline C6I4PU & 38.81 & 25.87 & 35.32 & 48.25 & 51.75 \\
\hline C5I5PU & 29.45 & 29.45 & 41.10 & 36.63 & 63.36 \\
\hline C4I6PU & 22.37 & 33.56 & 44.07 & 27.80 & 72.20 \\
\hline
\end{tabular}

The flexible backbones result in low strength and modulus while the high crosslink density leads to brittleness. For example, the tensile strength and Young's modulus of the polyurethane prepared from $\mathrm{CO}$ and hexamethylene diisocyanate are only 0.8 and $3.59 \mathrm{MPa}$, respectively, meanwhile the elongation at break is $31.6 \%$ [11]. Some studies have combined polymeric diols such as poly (ethylene glycol) and poly( $\varepsilon$-caprolactone) with castor oil to prepare polyurethanes [30,31]. Such a technique is useful to improve the toughness of CO-based polyurethanes. However, the enhancement in strength and modulus is limited, due to that the polymeric diols are flexible as well. In addition, the polymeric diols are derived from fossil-based resources, which would reduce the sustainability of the resultant materials.

The poor ductility of CO-based polyurethane results from the high crosslink density but not from poor flexibility of the network backbone. In fact, the network backbone is flexible enough. We don't need to incorporate flexible chains to improve the ductility. What we need to do is to reduce the crosslink density of the CO-based polyurethanes to improve the toughness. Therefore, it is not a good option to improve the mechanical properties of CO-based polyurethanes through combination of flexible polymeric diols. It is anticipated that simultaneous enhancement in both strength and ductility may be achieved if stiff structures were incorporated into the CO-based polyurethane to reduce crosslink density. The presence of stiff structures, on the one hand, increases the chain length between crosslinking sites, thus reduces the crosslink density and improves the ductility. On the other hand, the stiff structures enhance the stiffness of the resultant polyurethanes to reinforce the strength and modulus [32].

Renewable compounds with rigid structures are preferred as structure modifier for castor oil-based polyurethane from the viewpoint of sustainability. Isosorbide [33-35], a commercially available compound with double aliphatic rings, may be the good modifier for castor oilbased polyurethane. Besides the stiff nature, the hydroxyl of isosorbide is also secondary hydroxyl group, and thus has comparable activity with castor oil when reacting with diisocyanate. Herein, we report the fabrication of sustainable polyurethanes containing castor oil and isosorbide as well as the composition dependence of gel fraction, swelling ratio, mechanical properties and thermal stability of the polyurethanes in detail.

\section{EXPERIMENTAL SECTION}

\section{Materials}

Castor oil (CO, AR grade) was procured from the Micxy Chemical Co., Ltd. (Chengdu, China). Hexamethylene diisocyanate (HDI, 99\%) was obtained from the Aladdin Biochemical Technology Co. Ltd. (Shanghai, China). Isosorbide (IS, 98\%) was purchased from the Adamas Reagent Ltd. (Shanghai, China).

\section{Preparation of the sustainable polyurethanes}

The biobased polyurethanes were prepared via a two-step procedure, i.e., pre-curing and post curing. The pre-curing process was performed in a three-necked roundbottomed flask at $160^{\circ} \mathrm{C}$ for $20 \mathrm{~min}$. Predetermined amounts of $\mathrm{CO}$ and IS were added into the flask, which was then vacuumed and purged with $\mathrm{N}_{2}$ three times. Thereafter, predetermined amount of HDI was added into the flask and the reactants were stirred with a magnetic stirring bar for $20 \mathrm{~min}$ to complete pre-curing. In the post curing process, the pre-cured homogeneous mixture was further cured in a mold $(100 \times 100 \times$ $0.5 \mathrm{~mm}^{3}$ ) between two plates of a flat vulcanizing machine at $160^{\circ} \mathrm{C}$ under $10 \mathrm{MPa}$ for two hours. The molar ratio of $-\mathrm{NCO}$ to the total $-\mathrm{OH}$ was fixed at 1:1.

Six samples with CO/IS weight ratio of 9:1, 8:2, 7:3, 6:4, 5:5 and 4:6 were prepared and designated as C9I1PU, C8I2PU, C7I3PU, C6I4PU, C5I5PU and C4I6PU, respectively. For property comparison, the polyurethane consisting of $\mathrm{CO}$ and HDI was also prepared with the same procedures and was abbreviated as COPU. Table 1 lists the feeding contents of CO, IS and HDI during 
preparation of the samples.

\section{Fourier transform infrared (FT-IR) spectroscopy}

The FT-IR spectra were recorded on a RF-5301PC spectrophotometer (Shimadzu, Japan) from 4,000 to $400 \mathrm{~cm}^{-1}$ with the resolution and scanning number of $4 \mathrm{~cm}^{-1}$ and 32 times, respectively. The as-prepared sample sheets after curing under compression molding were used for FT-IR measurement.

\section{Gel fraction and swelling ratio}

The gel fraction and swelling ratio of the samples were measured through solvent swelling experiment. The sample with dimension of $10 \times 10 \times 0.5 \mathrm{~mm}^{3}$ and weight of $W_{0}$ was immersed in $25 \mathrm{~mL} \mathrm{~N}, \mathrm{~N}$-dimethylformamide for two days to reach swelling equilibrium. The swollen sample was weighed as $W_{1}$ after removing the surface solvent with filter paper. The swollen sample was then vacuum dried at $60^{\circ} \mathrm{C}$ for two days to obtain deswollen sample with weight of $W_{2}$. The gel fraction $\left(G_{\mathrm{f}}\right)$ was calculated by

$$
G_{\mathrm{f}}=\frac{W_{2}}{W_{0}} \times 100 \% .
$$

The swelling ratio $\left(S_{\mathrm{r}}\right)$ was calculated by

$$
S_{\mathrm{r}}=\frac{W_{1}-W_{0}}{W_{0}} \times 100 \% \text {. }
$$

\section{Tensile properties}

Tensile properties were measured on a MTS E44 universal testing machine at room temperature $\left(\sim 25^{\circ} \mathrm{C}\right)$ with a crosshead speed of $10 \mathrm{~mm} \mathrm{~min}^{-1}$ in general accordance with ISO 527-3. The standard dumbbell-shaped testing bars with width and thickness of 4.0 and $0.5 \mathrm{~mm}$ were cut from the sample sheet. The gauge length between the two pneumatic grips was $25 \mathrm{~mm}$. Averaged results were reported from five measurements for all the samples.

\section{Dynamic mechanical analysis (DMA)}

The dynamic mechanical properties were measured on a TA Instruments DMA Q800 analyzer using a tensile mode from -50 to $120^{\circ} \mathrm{C}$ at a heating rate of $3^{\circ} \mathrm{C} \mathrm{min}^{-1}$ and an oscillation frequency of $1 \mathrm{~Hz}$. The samples with dimension of $35 \mathrm{~mm}$ (length) $\times 6 \mathrm{~mm}$ (width) $\times 0.5 \mathrm{~mm}$ (thickness) were used for the measurement.

\section{Thermogravimetric analysis (TGA)}

Thermal stability of the biobased polyurethanes was studied by a TA Instruments TGA Q500 from room temperature to $600^{\circ} \mathrm{C}$ at a heating rate of $10^{\circ} \mathrm{C} \mathrm{min}{ }^{-1}$ under $\mathrm{N}_{2}$ atmosphere.

\section{RESULTS AND DISCUSSION}

\section{Preparation and characterization of the polyurethanes}

The castor oil based polyurethanes were prepared via a two-step procedure. The first step was performed in a flask at $160^{\circ} \mathrm{C}$ for $20 \mathrm{~min}$ to produce homogeneous precursors. In the second step, the precursors were cured in a mold at $160^{\circ} \mathrm{C}$ under $10 \mathrm{MPa}$ for $2 \mathrm{~h}$ to generate the polyurethane. Fig. 1 shows the reaction for the preparation of the polyurethane network from CO, IS and HDI and the digital photo of the typical sample sheet. The sample is almost colorless and translucent.

The chemical structures of the polyurethanes were characterized by FT-IR, as shown in Fig. 2. No absorption was observed at $2,200-2,300 \mathrm{~cm}^{-1}$ for all the samples, indicating that HDI was consumed completely during the two-step procedure curing process [36-38]. The two absorptions occurring at 1,745 and $1,695 \mathrm{~cm}^{-1}$ for COPU were attributed to the stretching vibration of carbonyls of ester and urethane groups, respectively $[15,39]$. The absorption of ester carbonyl becomes less prominent and that of urethane carbonyl becomes more prominent with increasing the IS content. The characteristic stretching vibration of $\mathrm{C}-\mathrm{O}-\mathrm{C}$ in ether group was observed at $\sim 1,100 \mathrm{~cm}^{-1}$ for all CIPUs $[40,41]$. The results indicated that the polyurethane containing IS unit was successfully synthesized.

The gel fraction and swelling behavior were investigated by a solution method to demonstrate the effect of IS content on the crosslink structure of the polyurethane networks, as shown in Fig. 3. The gel fraction of the control COPU was $97.5 \mathrm{wt} \%$, and the values were 98.4, 96.3, 94.5, 95.7, 94.6 and $93.8 \mathrm{wt} \%$ for C9I1PU, C8I2PU, C7I3PU, C6I4PU, C5I5PU and C4I6PU, respectively, which indicates that all the samples have crosslinked structure. Swelling ratio can be used to describe the crosslink density of network polymer qualitatively or semi-quantitatively, since the swelling ratio usually decreases with increasing crosslink density [42]. The crosslink density of CIPU should decrease with increasing IS content, due to the bi-functional structure of IS. The swelling ratio of COPU is $129 \%$. In accordance with the expectation, the swelling ratio increased apparently with increasing IS content and the values are $183 \%$, $190 \%, 228 \%, 300 \%, 350 \%$ and $420 \%$ for C9I1PU, C8I2PU, C7I3PU, C6I4PU, C5I5PU and C4I6PU, respectively, indicating reduced crosslink density with increasing IS content. 


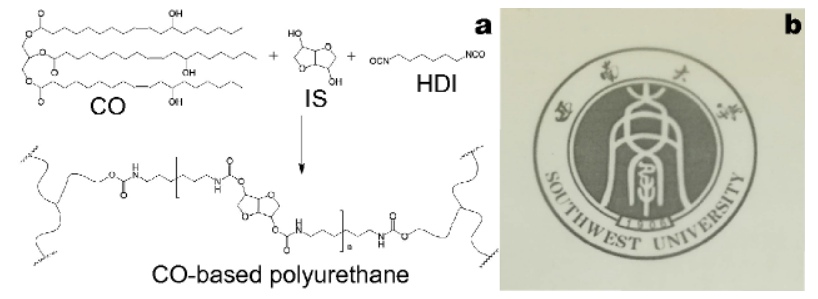

Figure 1 Reaction between $\mathrm{CO}$ and IS with HDI to fabricate the CObased polyurethane (a) and the photo of the prepared typical sample sheet (b).

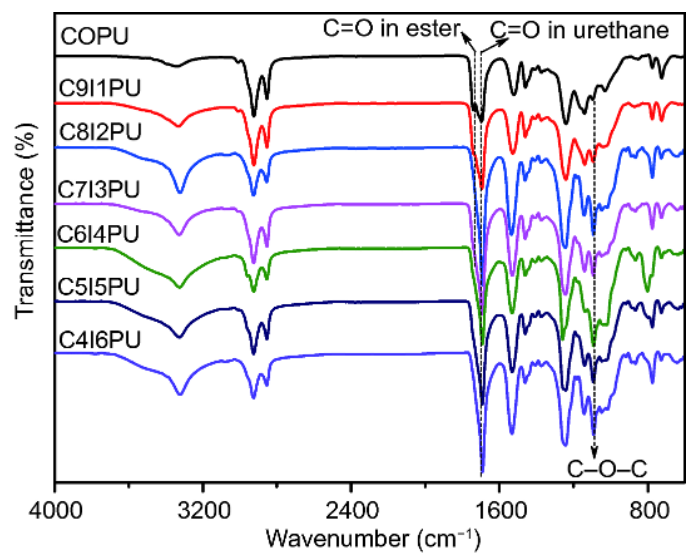

Figure 2 FTIR spectra of COPU and CIPUs with different compositions.

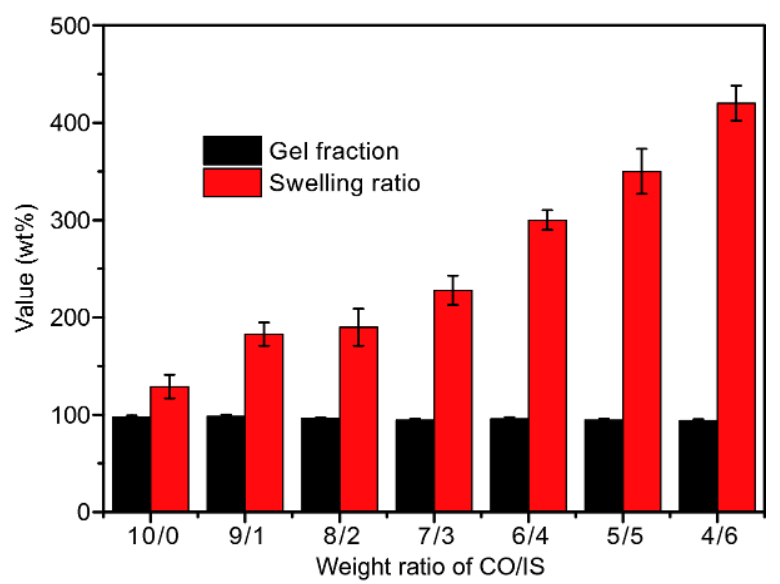

Figure 3 Gel fraction and swelling ratio as functions of weight ratio of $\mathrm{CO} / \mathrm{IS}$.

\section{Mechanical properties}

We studied the effect of composition on mechanical properties of the polyurethane network through tensile testing. Fig. 4 shows the stress-strain curves of COPU and CIPUs with different compositions. It is obvious that the control COPU with high crosslink density and flexible structure shows tensile behavior of soft and weak material with tensile stress $(\sigma)$ and elongation at break $(\varepsilon)$ of only $0.76 \pm 0.06 \mathrm{MPa}$ and $37 \% \pm 3 \%$, respectively. Interestingly, both $\sigma$ and $\varepsilon$ increased with increasing isosorbide content when the feed weight ratio of CO/IS is less than 5/5. C9I1PU, C8I2PU, C7I3PC and C6I4PU exhibited elastomer-like tensile behavior with $\sigma$ increased to $0.80 \pm$ $0.05,2.07 \pm 0.12,4.96 \pm 0.35$ and $12.89 \pm 0.63 \mathrm{MPa}$ and $\varepsilon$ increased to $42 \% \pm 4 \%, 71 \% \pm 8 \%, 200 \% \pm 15 \%, 363 \% \pm$ $20 \%$, respectively. The improvement in the $\sigma$ and the $\varepsilon$ was 16.9 and 10 times for C6I4PU compared to the control COPU. The results are in good agreement with our design principles to improve the strength and toughness of the polyurethane through incorporation of stiff unit to reduce the crosslink density. The stiffness of the sample can be described by Young's modulus $(E)$. The control COPU shows $E$ of $4.68 \pm 0.33 \mathrm{MPa}$. $E$ increases to $5.02 \pm 0.25, \quad 13.91 \pm 1.47, \quad 16.82 \pm 2.01$ and $19.01 \pm 3.43 \mathrm{MPa}$ for C9I1PU, C8I2PU, C7I3PC and C6I4PU, respectively, indicating gradually increased stiffness with increasing IS content. Surprisingly, C5I5PU and C4I6PU show a plastic-like tensile behavior especially for C4I6PU, with yielding appeared during stretching. $\varepsilon$ of C5I5PU and C4I6PU decrease to $214 \% \pm 15 \%$ and $198 \% \pm 17 \%$ while $\sigma$ of both increase to $\sim 34 \mathrm{MPa}$, which are 2.6 times that of C6I4PU. The significantly enhanced tensile strength should be attributed to the transformation of the network structure from flexibility to stiffness with CO/IS feed ratio changed from $6 / 4$ to $5 / 5$ and $4 / 6$. The polyurethanes are usually thought as segmented copolymers consisting of hard and soft segments. In this study, the soft segment (SS) is the moiety formed by reaction of CO with HDI and the hard segment (HS) is the moiety formed by reaction of IS with HDI. Table 1 lists the contents of both SS and HS calculated according to the feed ratio. For the samples with $\mathrm{CO} / \mathrm{IS}$ feed ratio of higher than $6 / 4$, the samples behave like elastomers due to that SS is the main component. With the CO/IS feed ratio decreased to less than $6 / 4$, the content of HS increased to much higher than that of SS, thus the samples changes to plastic-like tensile behavior with high Young's modulus. The $E$ value increased significantly from $54.15 \pm 11.45 \mathrm{MPa}$ for C5I5PU to $366.13 \pm 51.24 \mathrm{MPa}$ for C4I6PU, also indicating a drastic enhancement in stiffness with CO/IS feed ratio changed from $5 / 5$ to $4 / 6$.

The dynamic mechanical properties of COPU and CIPUs were investigated by DMA. Fig. 5 shows the dependence of storage modulus and $\tan \delta$ with temperature of COPU and CIPUs. COPU exhibits a single drop in the 


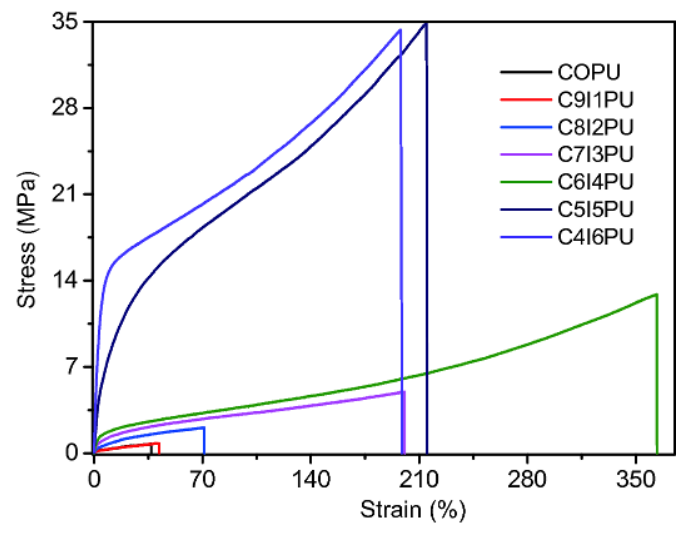

Figure 4 Stress-strain curves of COPU and CIPUs with different compositions.
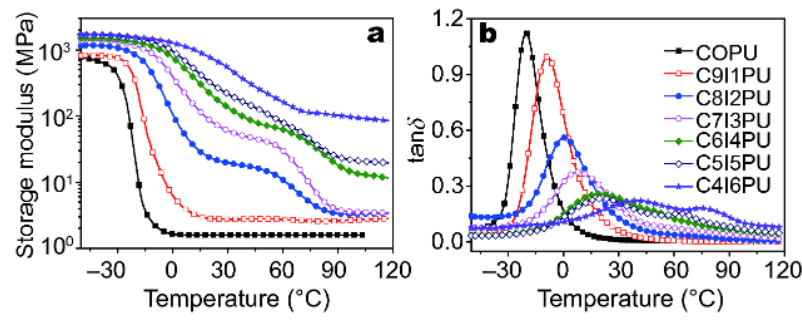

Figure 5 Storage modulus (a) and $\tan \delta$ (b) versus temperature of COPU and CIPUs.

storage modulus plot (Fig. 5a) and a sharp peak in the $\tan \delta$ plot (Fig. 5b), corresponding to the $a$-relaxation (glass transition) of COPU. The relaxation peak temperature was defined as the glass transition temperature $\left(T_{\mathrm{g}}\right)$. The $T_{\mathrm{g}}$ of COPU is $-20.5^{\circ} \mathrm{C}$. All CIPUs show two drops in the storage modulus plots, corresponding to the glass transition of the soft segment and hard segment, respectively, which indicates that phase separation occurred for the CIPUs. The $T_{\mathrm{g}}$ of SS with increasing HS content shifted to higher temperature range, while the $T_{\mathrm{g}}$ of the HS with increasing SS content shifted to lower temperature range, which suggests that the SS and the HS are partially miscible. The storage moduli of CIPUs are higher than that of COPU and increase with increasing HS content in the full temperature range, indicating reinforced mechanical performance due to the enhanced stiffness. The storage modulus at high temperature can be used to evaluate the heat resistance of a material, because higher storage modulus demonstrates better tolerance to external loading $[5,27,28]$. The storage modulus of COPU is only $1.59 \mathrm{MPa}$ and the value increases to $2.69,3.29$, $3.54,13.67,21.29$ and $94.8 \mathrm{MPa}$ for C9I1PU, C8I2PU,
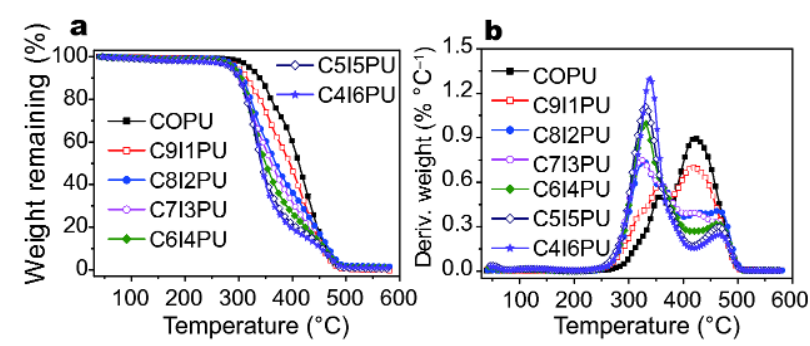

Figure 6 TGA (a) and DTG (b) curves of the control COPU and CIPUs with different compositions.

C7I3PU, C6I4PU, C5I5PU and C4I6PU, respectively, indicating enhanced heat resistance by incorporation of IS moiety. The damping peak height of the polyurethanes at low temperature range reduces gradually with increasing IS content (Fig. 5b), again relating to the enhanced stiffness, which restricts the molecular movement thus lowers the damping in transition zone.

\section{Thermal stability}

The thermal stability of the control COPU and CIPUs with different compositions was studied by TGA. Fig. 6 shows the TGA and DTG curves of the samples from room temperature to $600^{\circ} \mathrm{C}$ under $\mathrm{N}_{2}$ atmosphere. The control COPU showed two weight loss stages with the maximum decomposition temperatures $\left(T_{\max }\right)$ of 358 and $419^{\circ} \mathrm{C}$, corresponding to the thermal degradation of HID and $\mathrm{CO}$ moieties, respectively. CIPUs with different compositions also showed two weight loss stages with the two $T_{\max } \mathrm{S}$ at $\sim 330$ and $420-460^{\circ} \mathrm{C}$. The weight loss of the first stage increased while that of the second stage decreased with increase in IS content. Therefore, the first stage should be ascribed to the thermal degradation of IS and HDI moieties as their decomposition temperatures may overlap with each other and the second stage is the thermal degradation of $\mathrm{CO}$ moiety. The onset decomposition temperature, $T_{5}$ ( $5 \%$ weight loss temperature), is more commonly used to describe the thermal stability of materials. The $T_{5}$ of the control COPU is $320^{\circ} \mathrm{C}$ and the value decreases to $298,294,288,288,284$ and $285^{\circ} \mathrm{C}$ for C9I1PU, C8I2PU, C7I3PC, C6I4PU, C5I5PC and C4I6PU, respectively, which indicates that incorporation of IS moiety reduces the thermal stability of the polyurethane due to its low thermal decomposition temperature. Although the onset decomposition temperature reduced, the thermal stability of all CIPUs is still not too bad as the $T_{5}$ values are higher than $280^{\circ} \mathrm{C}$ for all the samples. 


\section{CONCLUSIONS}

In summary, we designed and fabricated a series of castor oil-based polyurethanes with stiff isosorbide as a structure modifier. All the polyurethanes with different compositions show gel fraction of higher than $93 \mathrm{wt} \%$. The crosslink density of the samples decreases with increasing IS content, as evidenced by the increasing swelling ratio. Meanwhile, the stiffness of the samples increases with increasing the IS content since all the tensile strength, Young's modulus and storage modulus increase with the IS content. Furthermore, the elongation at break of the polyurethanes containing IS units is also improved significantly compared to the control polyurethane without IS unit, which is attributed to the reduced crosslink density. The polyurethanes with tensile properties varied from elastomer to tough plastic were fabricated by controlling the compositions. The soft segment is partially miscible with the hard segment for the polyurethanes. The heat resistance of the polyurethanes also increases with increasing the IS content due to the increasing stiffness. All the polyurethanes exhibit good thermal stability with onset decomposition temperature of higher than $280^{\circ} \mathrm{C}$. The investigation demonstrates that incorporation of a stiff component to reinforce the stiffness and reduce crosslink density is a very efficient approach to improve the overall mechanical properties of flexible and highly crosslinked polymer networks.

Received 14 November 2017; accepted 21 December 2017; published online 16 January 2018

1 Yu L, Dean K, Li L. Polymer blends and composites from renewable resources. Prog Polymer Sci, 2006, 31: 576-602

2 Reddy MM, Vivekanandhan S, Misra M, et al. Biobased plastics and bionanocomposites: current status and future opportunities. Prog Poly Sci, 2013, 38: 1653-1689

3 Auvergne R, Caillol S, David G, et al. Biobased thermosetting epoxy: present and future. Chem Rev, 2014, 114: 1082-1115

4 Wang S, Ma S, Xu C, et al. Vanillin-derived high-performance flame retardant epoxy resins: facile synthesis and properties. Macromolecules, 2017, 50: 1892-1901

5 Si WJ, An XP, Zeng JB, et al. Fully bio-based, highly toughened and heat-resistant poly(L-lactide) ternary blends via dynamic vulcanization with poly(D-lactide) and unsaturated bioelastomer. Sci China Mater, 2017, 60: 1008-1022

6 Liu J, Ren W, Lu X. Fully degradable brush polymers with polycarbonate backbones and polylactide side chains. Sci China Chem, 2015, 58: 999-1004

7 Güner FS, Yağcı Y, Erciyes AT. Polymers from triglyceride oils. Prog Polym Sci, 2006, 31: 633-670

8 Zhang C, Garrison TF, Madbouly SA, et al. Recent advances in vegetable oil-based polymers and their composites. Prog Polym Sci, 2017, 71: 91-143

9 Li P, Ma S, Dai J, et al. Itaconic acid as a green alternative to acrylic acid for producing a soybean oil-based thermoset: synthesis and properties. ACS Sustain Chem Eng, 2017, 5: 1228-1236

10 Ding C, Shuttleworth PS, Makin S, et al. New insights into the curing of epoxidized linseed oil with dicarboxylic acids. Green Chem, 2015, 17: 4000-4008

11 Hablot E, Zheng D, Bouquey M, et al. Polyurethanes based on castor oil: kinetics, chemical, mechanical and thermal properties. Macromol Mater Eng, 2008, 293: 922-929

12 Zeng RT, Wu Y, Li YD, et al. Curing behavior of epoxidized soybean oil with biobased dicarboxylic acids. Polymer Testing, 2017, 57: 281-287

13 Kunduru KR, Basu A, Haim Zada M, et al. Castor oil-based biodegradable polyesters. Biomacromolecules, 2015, 16: 2572-2587

14 Yeganeh H, Mehdizadeh MR. Synthesis and properties of isocyanate curable millable polyurethane elastomers based on castor oil as a renewable resource polyol. Eur Polymer J, 2004, 40: 12331238

15 Allauddin S, Narayan R, Raju KVSN. Synthesis and properties of alkoxysilane castor oil and their polyurethane/urea-silica hybrid coating films. ACS Sustain Chem Eng, 2013, 1: 910-918

16 Madbouly SA, Xia Y, Kessler MR. Rheological behavior of environmentally friendly castor oil-based waterborne polyurethane dispersions. Macromolecules, 2013, 46: 4606-4616

17 Somani KP, Kansara SS, Patel NK, et al. Castor oil based polyurethane adhesives for wood-to-wood bonding. Int J Adhes Adhes, 2003, 23: 269-275

18 Athawale VD, Joshi KR. Structure-property relationship in polyurethane coatings synthesized from chemoenzymatically modified castor oil. J Polym Mater, 2004, 21: 165-173

19 Petrovic ZS. Polyurethanes from vegetable oils. Polymer Revs, 2008, 48: 109-155

20 Wik VM, Aranguren MI, Mosiewicki MA. Castor oil-based polyurethanes containing cellulose nanocrystals. Polym Eng Sci, 2011, 51: 1389-1396

21 Lin S, Huang J, Chang PR, et al. Structure and mechanical properties of new biomass-based nanocomposite: castor oil-based polyurethane reinforced with acetylated cellulose nanocrystal. Carbohydrate Polym, 2013, 95: 91-99

22 Meera KMS, Sankar RM, Paul J, et al. The influence of applied silica nanoparticles on a bio-renewable castor oil based polyurethane nanocomposite and its physicochemical properties. Phys Chem Chem Phys, 2014, 16: 9276-9288

23 Pinto ERP, Barud HS, Silva RR, et al. Transparent composites prepared from bacterial cellulose and castor oil based polyurethane as substrates for flexible OLEDs. J Mater Chem C, 2015, 3: 1158111588

24 Li M, Xia J, Mao W, et al. Preparation and properties of castor oilbased dual cross-linked polymer networks with polyurethane and polyoxazolidinone structures. ACS Sustain Chem Eng, 2017, 5: 6883-6893

25 Thakur S, Karak N. Ultratough, ductile, castor oil-based, hyperbranched, polyurethane nanocomposite using functionalized reduced graphene oxide. ACS Sustain Chem Eng, 2014, 2: 1195-1202

26 Li C, Sung J, Sun XS. Network from dihydrocoumarin via solventfree metal-mediated pathway: a potential structure for substantial toughness improvement of epoxidized plant oil materials. ACS Sustain Chem Eng, 2016, 4: 1231-1239

27 Jian XY, He Y, Li YD, et al. Curing of epoxidized soybean oil with crystalline oligomeric poly(butylene succinate) towards high performance and sustainable epoxy resins. Chem Eng J, 2017, 326: 
875-885

28 Jian XY, An XP, Li YD, et al. All plant oil derived epoxy thermosets with excellent comprehensive properties. Macromolecules, 2017, 50: 5729-5738

29 Jiang F, Fang C, Zhang J, et al. Triblock copolymer elastomers with enhanced mechanical properties synthesized by RAFT polymerization and subsequent quaternization through incorporation of a comonomer with imidazole groups of about 2.0 mass percentage. Macromolecules, 2017, 50: 6218-6226

30 Choi KK, Park SH, Oh KW, et al. Effect of castor oil/polycaprolactone hybrid polyols on the properties of biopolyurethane. Macromol Res, 2015, 23: 333-340

31 Yeganeh H, Hojati-Talemi P. Preparation and properties of novel biodegradable polyurethane networks based on castor oil and poly (ethylene glycol). Polym Degradation Stability, 2007, 92: 480-489

32 Jiang F, Wang Z, Qiao Y, et al. A novel architecture toward thirdgeneration thermoplastic elastomers by a grafting strategy. Macromolecules, 2013, 46: 4772-4780

33 Duan RT, He QX, Dong X, et al. Renewable sugar-based diols with different rigid structure: comparable investigation on improving poly(butylene succinate) performance. ACS Sustain Chem Eng, 2016, 4: 350-362

34 Galbis JA, García-Martín MG, de Paz MV, et al. Synthetic polymers from sugar-based monomers. Chem Rev, 2016, 116: 16001636

35 Xing DD, Jia YW, Li DF, et al. Novel multiblock poly(c-caprolactone) copolyesters containing $D$-glucose derivatives with different bicyclic structures. ACS Sustain Chem Eng, 2017, 5: 70407051

36 Zeng JB, Jiao L, Li YD, et al. Bio-based blends of starch and poly (butylene succinate) with improved miscibility, mechanical properties, and reduced water absorption. Carbohydrate Polym, 2011,
83: $762-768$

37 Zhao TH, He Y, Li YD, et al. Dynamic vulcanization of castor oil in a polylactide matrix for toughening. RSC Adv, 2016, 6: 7954279553

38 He YS, Zeng JB, Liu GC, et al. Super-tough poly(L-lactide)/ crosslinked polyurethane blends with tunable impact toughness. RSC Adv, 2014, 4: 12857-12866

39 Luo N, Wang D-N, Ying S-K. Hydrogen-bonding properties of segmented polyether poly(urethane urea) copolymer. Macromolecules, 1997, 30: 4405-4409

40 Zhang J, Han F, Wei X, et al. Spectral studies of hydrogen bonding and interaction in the absorption processes of sulfur dioxide in poly(ethylene glycol) 400 water binary system. Ind Eng Chem Res, 2010, 49: 2025-2030

41 Chen F, Hehl J, Su Y, et al. Smart secondary polyurethane dispersions. Polym Int, 2013, 62: 1750-1757

42 Pojanavaraphan T, Magaraphan R. Prevulcanized natural rubber latex/clay aerogel nanocomposites. Eur Polymer J, 2008, 44: 19681977

Acknowledgements This work has been supported by the National Natural Science Foundation of China (51703188), the Basic and Frontier Research Project of Chongqing (cstc2017jcyjAX0426) and the Fundamental Research Funds for the Central Universities (XDJK2017A016 and XDJK2017C022).

Author contributions An XP, Li YD and Zeng JB conceived and designed the experiments and wrote the article. An XP and Chen JH carried out the experiments. All the authors contributed to the discussion of the investigation.

Conflict of interest The authors declare no conflict of interest. 


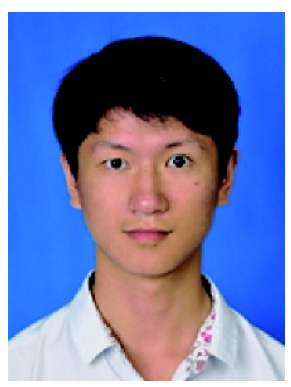

Xu-Pei An is a junior student majoring in Materials Science at Southwest University and his research project is highperformance modification of castor oil-based polymer networks.
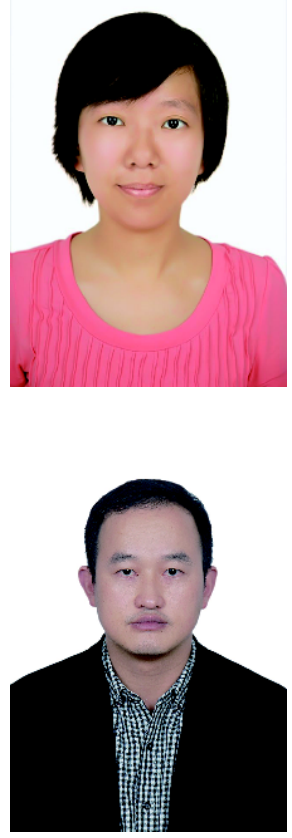

Yi-Dong $\mathbf{L i}$ is an associate professor of Southwest University. She received her PhD degree in 2010 from Sichuan University supervised by Prof. Yu-Zhong Wang. Her research interests focus on sustainable polymer design.
Jian-Bing Zeng is a professor of Southwest University. He received his PhD degree in 2009 from Sichuan University supervised by Prof. Yu-Zhong Wang. His research interests focus on high performance modification and functionalization of biobased/biodegradable polymers. He has published more than 80 articles in international journal such as Macromolecules, ACS Macro Lett., Biomacromolecules, Polym. Rev., ACS Sustainable Chem. Eng., Chem. Eng. J., Polym. Chem., Sci. China Mater. and Polymer.

\section{可持续葲麻油基聚氨酯的设计合成: 同时实现增强与增韧}

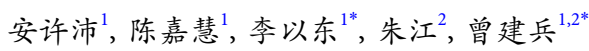

摘要 菎麻油基聚氨酯(COPU)链柔顺性大且交联密度高, 导致其力学强度与韧性俱差. 本文将双官能度刚性物质引入COPU, 一方面, 利 用其刚性增强COPU的力学强度与模量; 另一方面, 利用双官能度结构, 降低COPU的交联密度, 提升其韧性, 同时实现COPU的增韧与增 强. 我们将生物基异山梨醇(IS)用作COPU的结构调节单元, 设计合成了一系列生物基聚氨酯(CIPU). 研究发现: 当IS含量较少时, CIPU表 现出弹性体的拉伸行为, 其拉伸强度与断裂伸长率均随IS含量增加而大幅增加; 当IS含量高于菎麻油时, CIPU表现出塑料的拉伸行为, 拉 伸强度与断裂伸长率分别可达 34 MPa 与 200\%, 为COPU的 44 与5倍. 此外, 该CIPU还表现出优异的热稳定性与耐热性. 该研究可为植物 油基高分子新材料的设计合成提供借鉴. 